\title{
Spread of the Brazilian epidemic clone of a multiresistant MRSA in two cities in Argentina
}

\author{
MARCUS V. DA SILVA COIMBRA, LENISE A. TEIXEIRA*, ROSE L. B. RAMOS, SILVIA C. \\ PREDARI $\dagger$, LILIANA CASTELLO $\dagger$, ANGELA FAMIGLIETTI + CARLOS VAY $\$$, LILIAN KLAN $\S$ and \\ AGNES M. S. FIGUEIREDO
}

Universidade Federal do Rio de J aneiro, Instituto de Microbiologia Prof. Paulo de Góes, Laboratório de Biologia Molecular de Bactérias, Centro de Ciências da Saúde, Bloco I, Cidade Universitária, Rio de J aneiro, RJ 21941-590, *Universidade Federal Fluminense, Faculdade de Farmácia e Bioquímica, Rua Mário Vianna 523, Niterói, Rio de J aneiro, RJ 24241-000, Brazil, †Universidad de Buenos Aires, Facultad de Medicina, Instituto de Investigaciones Médicas Alfredo Lanari, Departamento de Microbiología, Combatientes de Malvinas 3150, (1427) Buenos Aires, tUniversidad de Buenos Aires, Facultad de Farmacia y Bioquímica, Hospital de Clínicas J osé de San Martín, Departamento de Bioquímica Clínica, Avenida Córdoba 2361, Buenos Aires and §Clinica de la Mujer, Córdoba 2422, Posadas, Provincia de Misiones, Argentina

M ethicillin-resistant Staphylococcus aureus (M RSA) is recognised as an important cause of nosocomial infection. The spread of some MRSA epidemic clones is well documented. In Brazil, and more recently in Portugal, a considerable number of hospital infections has been caused by a unique multiresistant MRSA clone designated as the Brazilian epidemic clone. This paper describes the spread of this clone in hospitals in two cities in Argentina.

\section{Introduction}

Methicillin-resistant Staphylococcus aureus (MRSA) has emerged and spread globally over the years since the first clinical use of methicillin. Once MRSA is introduced into a hospital it usually becomes endemic, despite the implementation of infection control measures $[1,2]$ and is an important cause of nosocomial infection $[2,3]$.

MRSA hospital isolates have been analysed by various chromosomal typing techniques [4]. These data have shown the predominance of some epidemic MRSA clones either in hospitals located in the same geographic area $[5,6]$, or separated by large distances [7-9]. Besides the rapid spread of these MRSA clones, epidemic MRSA are frequently multiresistant to antibiotics and susceptible only to vancomycin $[6,9]$. Furthermore, MRSA isolates showing reduced vancomycin susceptibility have recently been reported in Japan and the USA $[10,11]$.

In Brazil, it has been demonstrated that a multiresistant

Received 9 Feb. 1999; revised version received 12 July 1999; accepted 16 July 1999.

Corresponding author: Dr A. M. S. Figueiredo.
M RSA clone (Brazilian epidemic clone) is widespread geographically [9]. This clone has caused outbreaks in different cities ranging from $M$ anaus in the north to Porto A legre in the south $(5300 \mathrm{~km}$ apart). The great majority of MRSA strains isolated from Brazilian hospitals so far have shared a common pulsed-field gel electrophoresis (PFGE) pattern and the same ClalmecA and Clal-Tn554 patterns [9]. Recently, the intercontinental spread of the Brazilian epidemic clone to Portugal was demonstrated [7].

This study reports the spread of the Brazilian epidemic clone in A rgentina and the persistence of this clone in two hospitals in Rio de Janeiro during the last 5-6 years.

M aterials and methods

\section{Bacterial isolates}

A total of 80 isolates of MRSA was obtained from infections or nasal colonisation during the period 1992-1997 from three hospitals in two Argentine cities, Buenos Aires and Posadas (Provincia de Misiones), and from two hospitals in Rio de Janeiro, B razil. Nineteen of these isolates were from the Instituto de Investigaciones M édicas Alfredo Lanari, a 100-bed teaching hospital associated with the 
Universidad de Buenos Aires, specialising in nephrology and renal transplantation. Fourteen isolates were from the Hospital de Clínicas José de San Martín, a 500-bed general teaching hospital, also associated with the Universidad de Buenos Aires. These two hospitals are c. $7 \mathrm{~km}$ apart in Buenos Aires. Eighteen MRSA isolates were from the Hospital Regional Dr Ramón Madariaga in Posadas, Provincia de Misiones, about $1100 \mathrm{~km}$ from Buenos Aires. This general hospital serves Posadas City and neighbouring cities, including some in Paraguay. Ten other M RSA isolates were from the Hospital da Força Aérea do Galeão in Rio de Janeiro. This is a 120-bed hospital offering surgical and medical care (except obstetrics). Finally, 19 isolates were from the Hospital Universitário Clementino Fraga Filho, a 500-bed general teaching hospital in Rio de Janeiro.

Disk diffusion test

Disk diffusion tests were performed as recommended by the National Committee for Clinical Laboratory Standards [12]. The antimicrobial drugs tested were: oxacillin $1 \mu \mathrm{g}$, penicillin $10 \mathrm{U}$, cephalothin $30 \mu \mathrm{g}$, clindamycin $2 \mu \mathrm{g}$, chloramphenicol $30 \mu \mathrm{g}$, ciprofloxacin $5 \mu \mathrm{g}$, erythromycin $15 \mu \mathrm{g}$, tetracycline $30 \mu \mathrm{g}$, gentamicin $10 \mu \mathrm{g}$, rifampin $5 \mu \mathrm{g}$, vancomycin $30 \mu \mathrm{g}$ and trimethoprim-sulphamethoxazole 1.25-23.75 $\mu \mathrm{g}$.

\section{DNA preparation}

All the procedures for $S$. aureus DNA preparation were as described previously [13], except that the staphylococcal cell wall was lysed by lysostaphin $90 \mathrm{U} / \mathrm{ml}$. Escherichia coli plasmid DNA was prepared with the Flex-Prep kit (Pharmacia Biotechnology) as recommended by the manufacturer. The DNA fragment of $E$. coli plasmid (used as probe) was purified from an agarose $0.8 \%$ gel DNA electrophoresis with the Sephaglas B and Prep kit (Pharmacia), as recommended by the manufacturer.

\section{PFGE}

Preparation of cells and Sma I digestion of genomic DNA were performed as described previously [9]. PFGE was performed in a counter-clamped homogeneous electric field (CHEF) DR III apparatus (BioRad) for $23 \mathrm{~h}$ at $11^{\circ} \mathrm{C}$. Running conditions were: the voltage was set at $5.5 \mathrm{~V} / \mathrm{cm}$, ramped with an initial forward time of $1 \mathrm{~s}$ and a final forward time of $30 \mathrm{~s}$. After electrophoresis, gels were stained with ethidium bromide $(1 \mu \mathrm{g} / \mathrm{ml})$ for $30 \mathrm{~min}$ and photographed over a UV transilluminator after washing for $1 \mathrm{~h}$ in distilled water. Southern blotting of the DNA gels was as described previously [13]. The DNA was hybridised with a specific IS257 probe, a 630-bp HindIII fragment cloned into plB 1644 [14]. Bacterial clones were defined as proposed by Tenover et al. [4].
Determination of Clal-mecA polymorphism

Chromosomal DNA from all MRSA isolates was digested with Clal and, after Southern blotting, the membranes were hybridised with a specific mecA probe, a 1250-bp Pstl-Xbal fragment of the mecA gene cloned into pTZ219 [15].

\section{Probe preparation}

The procedure to obtain the fluorescein-labelled probe by the Enhanced Chemiluminescence (ECL) Gene Labelling System was performed as recommended by the manufacturer (A mersham).

\section{Results}

\section{Antibiotic resistance phenotype}

The 80 MRSA isolates studied were divided into two groups according to their antibiotic susceptibility patterns. The majority of the isolates (72) were susceptible only to vancomycin or to vancomycin and a combination of one or two of chloramphenicol, rifampin and ciprofloxacin. The second group (eight isolates) were susceptible to vancomycin and to five to six other drugs (Table 1 ).

\section{PFGE patterns}

To confirm the persistence of the Brazilian epidemic clone in hospitals in Rio de Janeiro, the PFGE patterns of 29 isolates that were colonising or causing infection in patients from two hospitals in this city were analysed. All the isolates from these Brazilian hospitals had a PFGE pattern designated $A_{1}$ that was indistinguishable from the pattern of the Brazilian epidemic clone (Table 1).

The analysis of the PFGE patterns of the 18 MRSA isolates from Hospital Ramón Madariaga in Posadas, Provincia de Misiones, Argentina, during 1995 and 1996, showed four major patterns, designated A-D. Eight of these isolates had a pattern, designated A, indistinguishable from that of strains belonging to the Brazilian epidemic clone. Six other isolates had another major pattern designated B, two had a pattern named $C$ and two had pattern D. Strains designated pattern $C$ had only four PFGE bands different from the Brazilian epidemic clone and thus they are closely related MRSA isolates (Fig. 1a, b; Table 1).

Strains belonging to the Brazilian epidemic clone and its subclones (strains differing by only one to three PFGE bands) were also found among the isolates from Instituto de Investigaciones Médicas in Buenos Aires (nine of 19 isolates). In addition, four isolates with pattern $D$ were shown to cause infection in this hospital. Other sporadic clones were identified among 
Table 1. Antibiotic susceptibility and PFGE patterns of the MRSA strains isolated from Brazil and Argentina

\begin{tabular}{|c|c|c|c|c|}
\hline City & Hospital & Antibiotic susceptibility & PFGE pattern & $\begin{array}{l}\text { Number of } \\
\text { isolates }\end{array}$ \\
\hline RJ & HFAG & Vc & $A_{1}$ & 10 \\
\hline RJ & HUCFF & Vc & $A_{1}$ & 8 \\
\hline Rj & HUCFF & $\mathrm{VcCO}$ & $A_{1}$ & 5 \\
\hline Rj & HUCFF & VcCip & $A_{1}$ & 2 \\
\hline Rj & HUCFF & $V c R f$ & $A_{1}$ & 4 \\
\hline Posadas & $\mathrm{HM}$ & $\mathrm{Vc}$ & $A_{1}$ & 7 \\
\hline Posadas & HM & VcCoRf & $A_{1}$ & 1 \\
\hline Posadas & $\mathrm{HM}$ & Vc & $B_{1}$ & 2 \\
\hline Posadas & HM & VcCoCISftCipTc & $B_{1}$ & 1 \\
\hline Posadas & HM & VcCoCISftCipTc & $\mathrm{B}_{2}$ & 1 \\
\hline Posadas & $\mathrm{HM}$ & VcCoCISftCipTc & $\mathrm{B}_{3}$ & 2 \\
\hline Posadas & HM & $\mathrm{VcCo}$ & $C_{1}$ & 1 \\
\hline Posadas & $\mathrm{HM}$ & $\mathrm{VcCo}$ & $C_{2}$ & 1 \\
\hline Posadas & $\mathrm{HM}$ & VcCoClSft & $D$ & 2 \\
\hline BA & IIM & Vc & $A_{1}$ & 5 \\
\hline BA & IIM & $\mathrm{VcCO}$ & $\mathrm{A}_{3}$ & 1 \\
\hline BA & IIM & Vc & $A_{4}$ & 2 \\
\hline BA & IIM & Vc & $A_{6}$ & 1 \\
\hline BA & IIM & Vc & D & 1 \\
\hline BA & IIM & VcCo & D & 1 \\
\hline BA & IIM & V cCoCISftTc & D & 2 \\
\hline BA & IIM & VcCipRf & $\mathrm{E}_{1}$ & 1 \\
\hline BA & IIM & Vc & $E_{2}$ & 1 \\
\hline BA & IIM & VcCipRf & $E_{2}$ & 1 \\
\hline BA & IIM & VcCo & $\mathrm{F}$ & 1 \\
\hline BA & IIM & Vc & G & 1 \\
\hline BA & IIM & Vc & $\mathrm{H}_{2}$ & 1 \\
\hline BA & $\mathrm{HC}$ & Vc & $A_{1}$ & 5 \\
\hline BA & $\mathrm{HC}$ & Vc & $A_{2}$ & 2 \\
\hline BA & $\mathrm{HC}$ & Vc & $A_{5}$ & 1 \\
\hline BA & $\mathrm{HC}$ & Vc & $\mathrm{C}_{1}$ & 2 \\
\hline BA & $\mathrm{HC}$ & Vc & $\mathrm{C}_{2}$ & 1 \\
\hline BA & $\mathrm{HC}$ & VcRfCip & $D$ & 1 \\
\hline BA & $\mathrm{HC}$ & Vc & $\mathrm{H}_{1}$ & 1 \\
\hline BA & $\mathrm{HC}$ & VcRf & 1 & 1 \\
\hline
\end{tabular}

HFAG, Hospital de Força Aérea do Galeão; HUCFF, Hospital Universitário Clementino Fraga Filho; HM, Hospital Ramón Madariaga; IIM, Instituto de Investigaciones M édicas; HC, Hospital de Clínicas José de San Martín.

RJ, Rio de Janeiro; BA, Buenos Aires.

Vc, vancomycin; Co, chloramphenicol; Cip, ciprofloxacin; Rf, rifampin; $\mathrm{Cl}$, clindamycin; Sft, sulphamethoxazole-trimethoprim; Tc, tetracycline.

the isolates analysed and were designated as patterns $\mathrm{E}-\mathrm{H}$ (Table 1).

Isolates with PFGE patterns similar to that of the B razilian epidemic clone, and also subclones of this clone, were observed to cause localised and disseminated infections in eight of 14 patients in another hospital in Buenos Aires (Hospital de Clínicas José de San Martín), and strains with patterns $C$ (observed in the hospital in Posadas city) and $D$ (observed in Posadas and in the Instituto de Investigaciones Médicas, Buenos Aires) were also shown to cause infection in patients in this hospital (Table 1). Sporadic isolates with PFGE pattern $H$ caused infections in patients in this hospital and in the Instituto de Investigaciones Médicas de Buenos Aires. Finally, another clone, designated as clone I, was also isolated (Table 1).

mecA polymorphism and IS257 insertion pattern

All isolates from Argentina that had a PFGE pattern indistinguishable from, or very similar to, that of the
Brazilian epidemic clone also had the same physical location for the mecA gene in $\mathrm{S}$. aureus chromosome. Furthermore, the isolates had a similar pattern of insertion for IS257 (Fig. 2a, b).

\section{Discussion}

DNA typing techniques are useful tools for distinguishing different bacterial strains of the same species [4]. Epidemiological studies using molecular analysis have provided new insights into the origin and evolution of pathogenic bacteria. This approach was used to study the spread and evolution of a unique MRSA clone in B razil $[9,16,17]$. This study looked for this clonal type in another South A merican country, Argentina. After restriction with the endonuclease Smal, the fragment patterns of the genomic DNA of 51 MRSA isolates from three A rgentinian hospitals and 29 MRSA isolates from two Brazilian hospitals were determined by PFGE. This showed that $25(49 \%)$ of the 51 Argentinian isolates belonged to PFGE pattern A (a pattern similar to that of the Brazilian epidemic clone), 
a

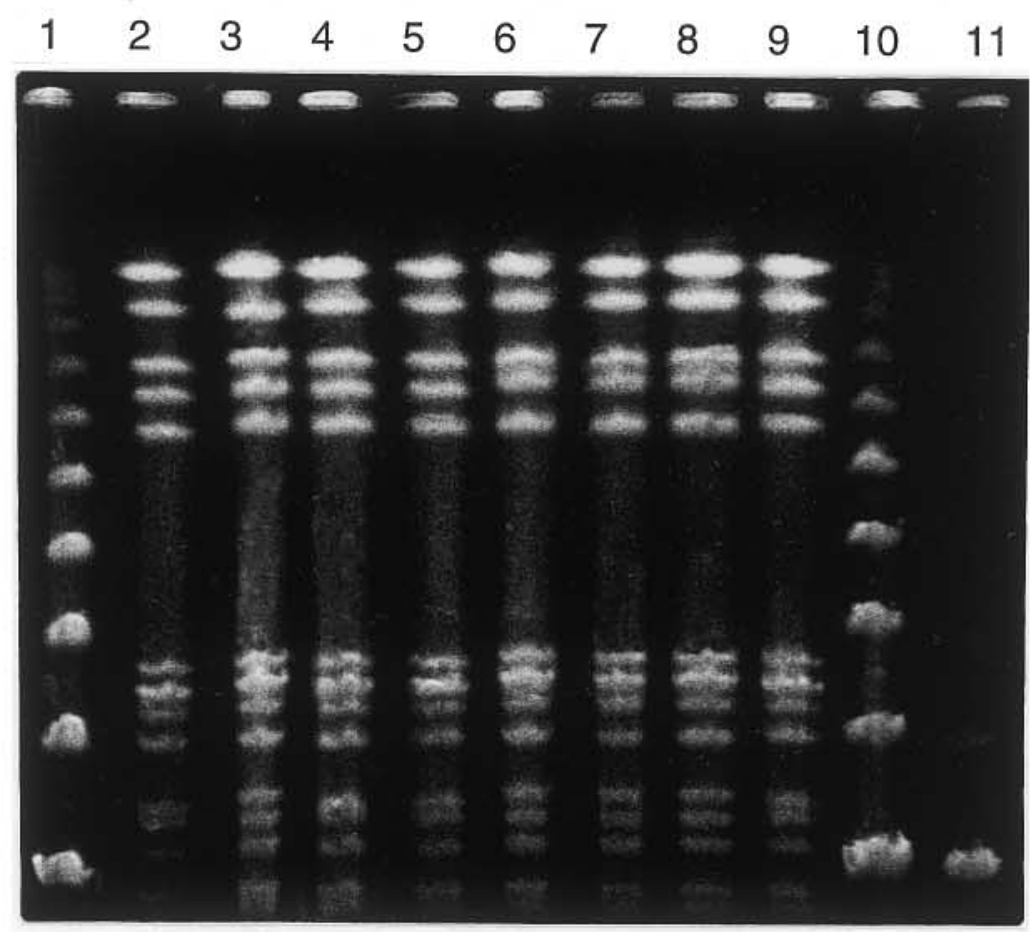

b

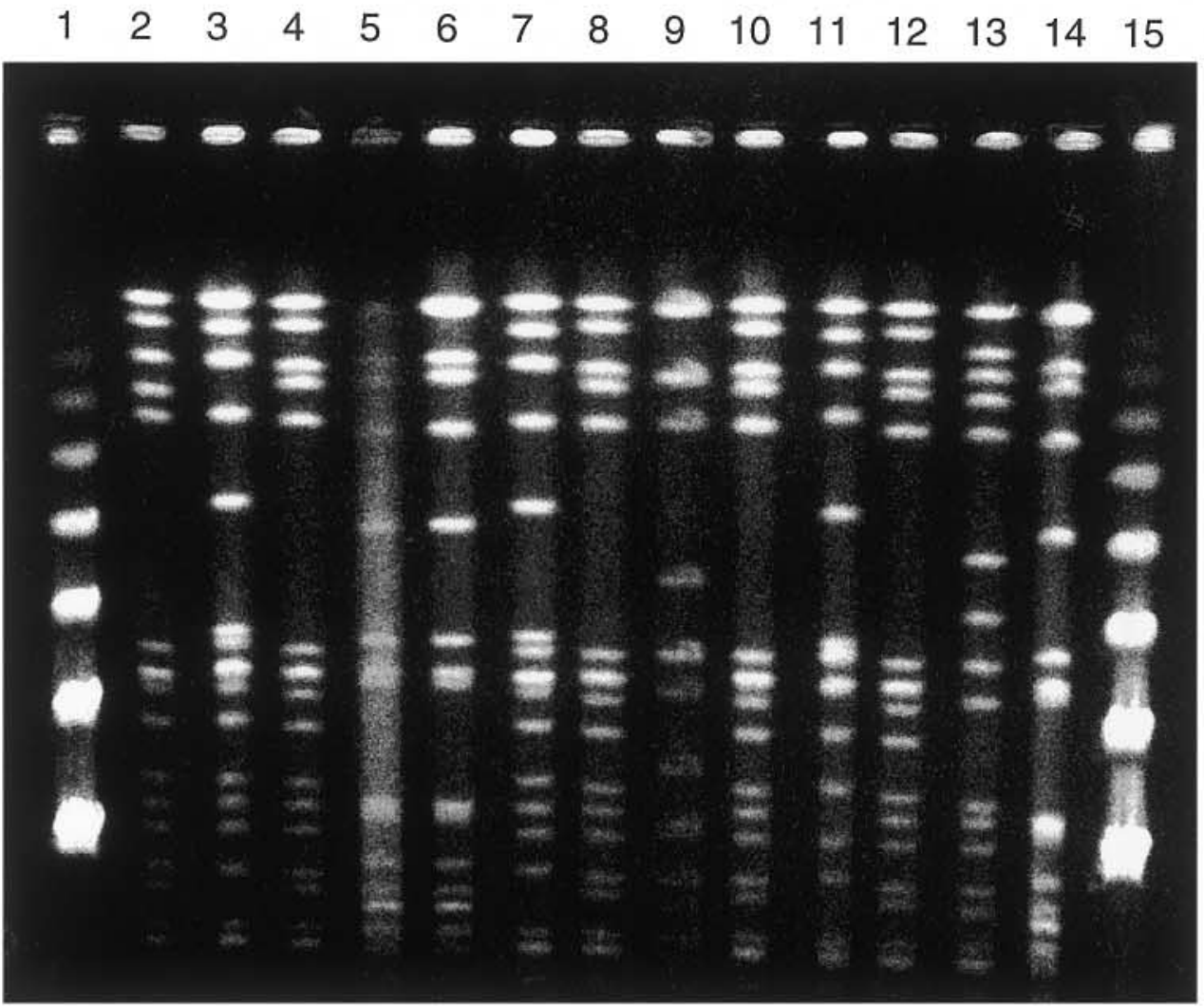

Fig. 1. PFGE patterns of the MSRA isolates from Argentinian and Brazilian hospitals. (a) Isolates with a pattern similar to the Brazilian epidemic clone. Lane 1, $\lambda$ ladder; 2, MRSA strain BMB5292 (Brazilian epidemic clone [9]; 3-5, MRSA isolates from Argentinian hospitals; 6, MRSA strain BMB 5292; 7, 8, isolates from two B razilian hospitals; 9, MRSA strain BMB 5292; 10, $\lambda$ ladder; $11, \lambda$ low mol. range. (b) MRSA isolates exhibiting PFGE patterns A-E. Lane $1, \lambda$ ladder; 2 , subclone of the Brazilian epidemic clone (PFGE pattern A); 3 , PFGE pattern $C$; 4 , PFGE pattern $A ; 5,6$, pattern $D ; 7$, pattern $C$; 8 , pattern $A ; 9$, pattern $B ; 10$, pattern $A ; 11$ pattern $C ; 12$, pattern $A ; 13$, pattern $L$; 14 , pattern $D ; 15, \lambda$ ladder. 
a
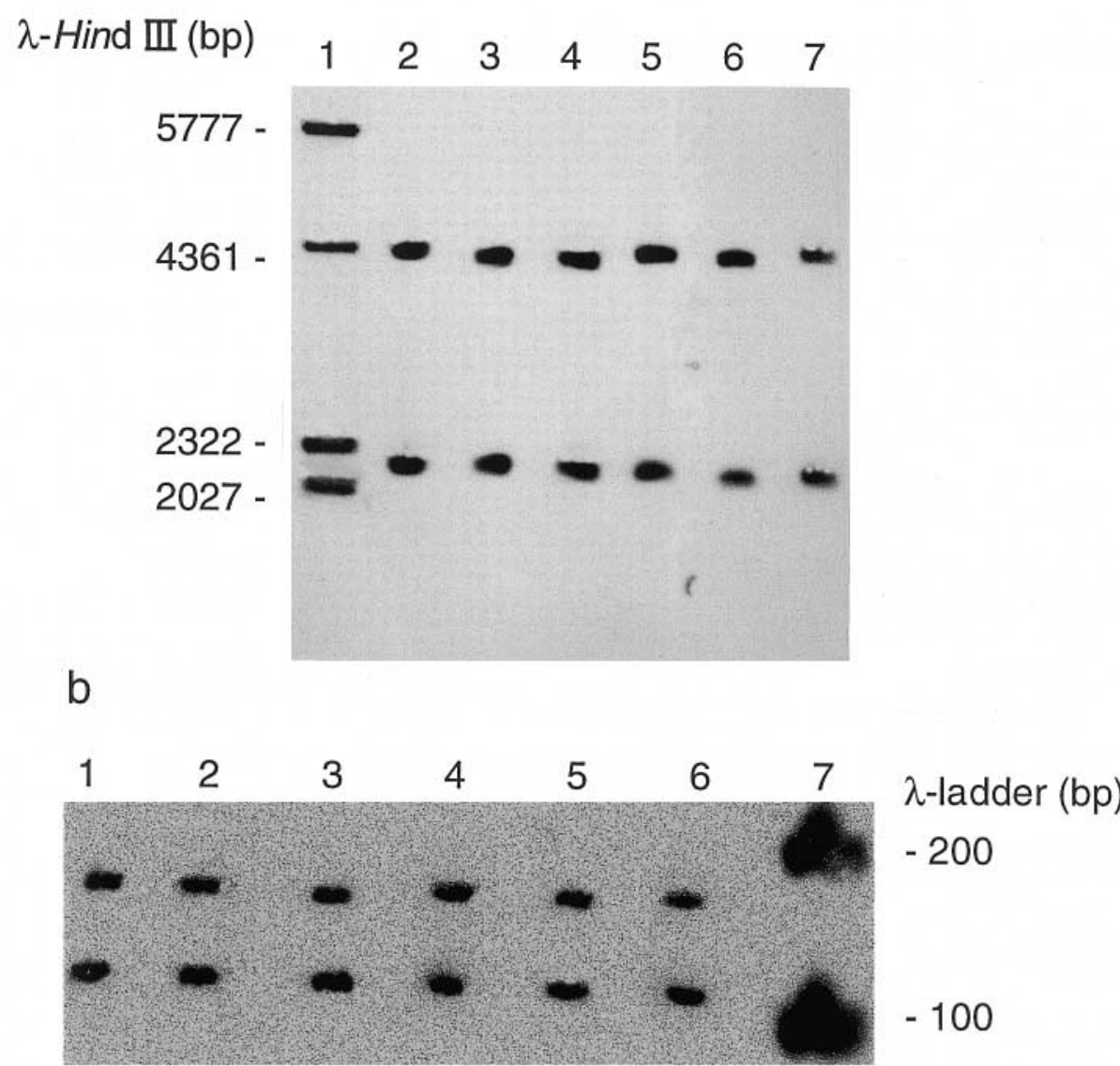

Fig. 2. Polymorphism of the mec region among MRSA strains isolated from Argentina and Brazil, exhibiting PFGE pattern A. (a) mecA-Clal polymorphism. Lane $1, \lambda$-H indlII; 2-4, isolates from the three hospitals in Argentina; 5,6 , isolates from the two hospitals in Rio de Janeiro; 7, strain BMB 5292, a representative of the Brazilian epidemic clone. (b) IS257 insertion pattern. Lanes 1-3, isolates from A rgentina; 4, B M B 5292 (Brazilian epidemic clone); 5, 6, isolates from Rio de Janeiro.

six $(12 \%)$ belonged to pattern $B$, five $(10 \%)$ to pattern $\mathrm{C}$ (very closely related to the Brazilian epidemic clone), seven (14\%) to pattern $D$ and the remaining eight isolates belonged to five sporadic patterns $(E, F$, $\mathrm{G}, \mathrm{H}$ and I). PFGE pattern A was observed in all three A rgentinian hospitals studied and strains with patterns $C, D$ and $H$ had caused infection in patients in hospitals in Posadas city and in Buenos Aires.

The spread of some MRSA clones over large distances may reflect an enhanced ability to spread and colonise patients in hospitals. Although some studies have compared the virulence of epidemic and sporadic MRSA clones, no conclusive data have been published so far. It was shown that some epidemic and nonepidemic MRSA isolates could be discriminated on the basis of protein $A$ gene polymorphism. However, the relationship between virulence and increased number of protein A repeat domains is unclear [18].

The 29 MRSA isolates from Rio de Janeiro hospitals, all belonging to the Brazilian epidemic clone, reflected the predominance and persistence of this unique M RSA clone in Rio in the last 5- 6 years [9].
To confirm that the strains with PFGE pattern A from three hospitals in Argentina belonged to the Brazilian clone, the mecA region of these isolates was investigated with two DNA probes: (i) a mecA probe and (ii) an IS257-specific probe. All isolates tested exhibited the same mecA IS257 patterns as that in the B razilian epidemic clone [9]. These results confirm that the B razilian epidemic clone has also spread and seems to predominate in some Argentinian hospitals. More recently, the spread of MRSA isolates from the $B$ razilian epidemic clone in Portugal and its rapid displacement of the Iberian clone (an epidemic M RSA clone that was found in Spain, Portugal, Italy and Scotland) by the Brazilian clone, has been reported $[7,19]$.

Hitherto, the spread and predominance of some specific clones of M RSA over large geographic areas have been poorly understood. The potential social and economic impact of MRSA infection caused by isolates belonging to the Brazilian epidemic clone can be predicted by its alarmingly rapid spread and by its ability to acquire new genes, including high-level mupirocin resistance [16]. 
Thus, it is recommended that South American and European health authorities pay special attention to the rapid spread of the Brazilian epidemic clone in hospitals. Further studies are needed to investigate what factors endow isolates of this MRSA clone type with their remarkable ability to spread.

A.M .S.F. was supported in part by a grant from Conselho Nacional de Desenvolvimento Científico e Tecnológico (CNPq), Financiadora de Estudos e Projetos (FINEP-PRONEX) and Fundação de Amparo a Pesquisa do Estado do Rio de Janeiro, Brazil. M.V.S.C. was the recipient of a fellowship from Fundação Coordenação de Aperfeiçoamento de Pessoal do Ensino Superior (CAPES).

\section{References}

1. Boyce JM. Methicillin-resistant Staphylococcus aureus: a continuing infection control challenge. Eur J Clin Microbiol Infect Dis 1994; 13: 45- 49.

2. Maple PAC, Hamilton-Miller JMT, Brumfitt W. Worldwide antibiotic resistance in methicillin-resistant Staphylococcus aureus. Lancet 1989; 1: 537-540.

3. Voss A, Milatovic D, Wallrauch-Schawarz C, Rosdahl VT, B raveny I. Methicillin-resistant Staphylococcus aureus in Europe. Eur J Clin Microbiol Infect Dis 1994; 13: 50-55.

4. Tenover FC, Arbeit $R$, Archer $G$ et al. Comparison of traditional and molecular methods of typing isolates of Staphylococcus aureus. J Clin Microbiol 1994; 32: 407-415.

5. de Lencastre H, Couto I, Santos I, Melo-Cristino J, TorresPereira A, Tomasz A. Methicillin-resistant Staphylococcus aureus disease in a Portuguese hospital: characterization of clonal types by a combination of DNA typing methods. Eur J Clin Microbiol Infect Dis 1994; 13: 64-73.

6. Dominguez MA, de Lencastre H, Linares I, Tomasz A. Spread and maintenance of a dominant methicillin-resistant Staphylococcus aureus (MRSA) clone during an outbreak of MRSA disease in a Spanish hospital. J Clin Microbiol 1994; 32 2081- 2087.

7. Aires de Souza M, Sanches IS, Ferro ML et al. Intercontinental spread of a multidrug-resistant methicillin-resistant Staphylococcus aureus clone. I Clin Microbiol 1998; 36: 2590-2596.
8. Santos Sanches I, Ramirez M, Troni $\mathrm{H}$ et al. Evidence for the geographic spread of a methicillin-resistant Staphylococcus aureus clone between Portugal and Spain. J Clin Microbiol 1995; 33: 1243- 1246.

9. Teixeira LA, Resende CA, Ormonde LR et al. Geographic spread of epidemic multiresistant Staphylococcus aureus clone in Brazil. J Clin Microbiol 1995; 33: 2400-2404.

10. Center for Disease Control and Prevention. Staphylococcus aureus with reduced susceptibility to vancomycin - United States, 1997. Morbid Mortal Wkly Rep 1997; 46: 765-766.

11. Hiramatsu K, Hanaki $H$, Ino $T$, Yabuta K, Oguri $T$, Tenover FC. Methicillin-resistant Staphylococcus aureus clinical strain with reduced vancomycin susceptibility. I Antimicrob Chemother 1997; 40: 135-136.

12. National Committee for Clinical Laboratory Standards. Performance standards for antimicrobial disk susceptibility tests, 6th edn. A pproved standard M2-A5. Wayne, PA, National Committee for Laboratory Standards. 1995.

13. Sambrook J, Fritsch EF, Maniatis T. Molecular cloning: a laboratory manual, 2nd edn. Cold Spring Harbor, NY, Cold Spring Harbor Laboratory Press. 1989.

14. Needham C, Rahman M, Dyke KGH, Noble WC. An investigation of plasmids from Staphylococcus aureus that mediate resistance to mupirocin and tetracycline. Microbiology 1994; 140: 2577-2583.

15. Matthews PR, Reed KC, Stewart PR. The cloning of chromosomal DNA associated with methicillin and other resistances in Staphylococcus aureus. J Gen Microbiol 1987; 133: $1919-1929$.

16. Ramos RLB, Teixeira LA, Ormonde LR, Siqueira PLA, $M$ arangoni $D$, Figueiredo AMS. Emergence of mupirocin resistance in multiresistant Staphylococcus aureus clinical isolates belonging to Brazilian epidemic clone III::B:A. J Med Microbiol 1999; 48: 303-308.

17. Soares MIS, Tokumaru-M iyazaki NH, Noleto ALS, Figueiredo AMS. Enterotoxin production by Staphylococcus aureus clones and detection of Brazilian epidemic MRSA clone (III::B:A) among isolates from food handlers. J Med Microbiol 1997; 46: 214-221.

18. Frénay $H M E$, Theelen JPG, Schouls $L M$ et al. Discrimination of epidemic and nonepidemic methicillin-resistant Staphylococcus aureus strains on the basis of protein $A$ gene polymorphism. J Clin Microbiol 1994; 32: 846-847.

19. $M$ ato $R$, Santos Sanches I, Venditti $M$ et al. Spread of the multiresistant Iberian clone of methicillin-resistant Staphylococcus aureus (MRSA) to Italy and Scotland. Microb Drug Resist 1998; 4: 107-112. 